\title{
The impact of concomitant pulmonary hypertension on early and late outcomes following surgery for mitral stenosis
}

\author{
Bo Yang, MD, PhD, ${ }^{\text {a }}$ Christina DeBenedictus, BS, ${ }^{\mathrm{b}}$ Tessa Watt, MD, ${ }^{\mathrm{a}}$ Sean Farley, BS, ${ }^{\mathrm{c}}$ Alona Salita, BS, ${ }^{\mathrm{d}}$ \\ Whitney Hornsby, PhD, ${ }^{\mathrm{e}}$ Xiaoting $\mathrm{Wu}, \mathrm{PhD},{ }^{\mathrm{a}}$ Morley Herbert, $\mathrm{PhD},{ }^{\mathrm{f}}$ Donald Likosky, PhD, ${ }^{\mathrm{a}}$ and \\ Steven F. Bolling, MD ${ }^{a}$
}

\begin{abstract}
Objectives: To provide initial evidence on the management of mitral stenosis and pulmonary hypertension $(\mathrm{PH})$ based on short-term and long-term outcomes following mitral valve surgery.

Methods: Consecutive patients with mitral stenosis $(\mathrm{n}=317)$ who had undergone mitral valve surgery between 1992 and 2014 with recorded pulmonary artery pressure (PAP) data were reviewed. PH severity, based on systolic PAP, was categorized as mild ( 35 to $44 \mathrm{~mm} \mathrm{Hg}$ ), moderate (45 to $59 \mathrm{~mm} \mathrm{Hg}$ ), or severe ( $>60 \mathrm{~mm} \mathrm{Hg}$ ). Primary outcomes were 30-day mortality and long-term survival.

Results: There were no significant between-group differences in age or preoperative comorbidities. Mitral valve surgery included mitral valve replacement $(78 \%)$ and repair $(22 \%)$. The severe PH group had more mitral valve replacement $(81 \%$; $P=.04)$, severe tricuspid valve regurgitation $(31 \% ; P=.003)$, right heart failure $(17 \% ; P=.02)$, and concomitant tricuspid valve procedures $(46 \% ; P<.001)$. For severe PH, 30-day mortality was $9 \%$, with no significant group differences. Ten- and 12-year survival were significantly worse in the moderate-severe $\mathrm{PH}$ group (58\% and 51\%, respectively) compared with the normal PAP-mild PH group ( $83 \%$ and $79 \%$, respectively) with a hazard ratio of 2.98 (95\% confidence interval, $1.55-5.75 ; P=.001)$. Ten-year survival after mitral valve surgery for mitral stenosis was inversely associated with preoperative PAP.
\end{abstract}

Conclusions: Mitral valve surgery can be performed with acceptable 30-day mortality for patients with mitral stenosis and moderate to severe $\mathrm{PH}$, but long-term survival is impaired by moderate to severe PH. Patients with mitral stenosis and mild PH (systolic PAP 35-44 mm Hg) should be considered for mitral valve surgery. (J Thorac Cardiovasc Surg 2016;152:394-400)

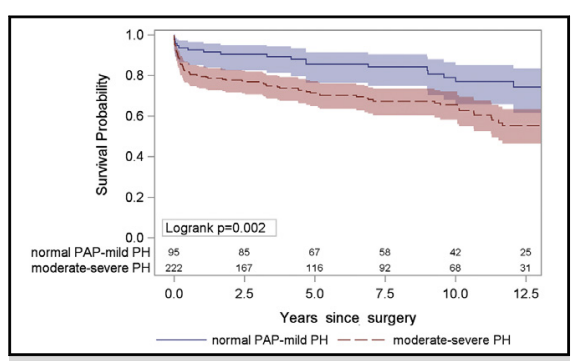

Survival stratified by moderate-severe $\mathrm{PH}$ versus normal PAP-mild PH.

\section{Central Message}

For patients undergoing mitral valve surgery for mitral stenosis, long-term survival was worse in those with moderate-severe pulmonary hypertension.

\section{Perspective}

Long-term survival diminished in patients with mitral stenosis after mitral valve surgery in the combined moderate-severe pulmonary hypertension group compared with the combined normal pulmonary artery pressure-mild pulmonary hypertension group. Our findings suggest that patients with severe mitral stenosis and mild pulmonary hypertension should be considered for mitral valve surgery.

See Editorial Commentary page 401.

See Editorial page 302.
From the Departments of ${ }^{\text {a }}$ Cardiac Surgery and ${ }^{\mathrm{e}}$ Internal Medicine, University of Michigan Health System, and ${ }^{\mathrm{b}}$ University of Michigan Medical School, Ann Arbor; ${ }^{\mathrm{c}}$ College of Human Medicine and ${ }^{\mathrm{d}}$ College of Osteopathic Medicine, Michi-

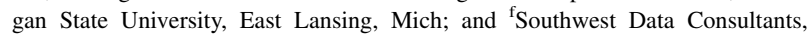
Dallas, Tex.

The authors attest that they had full freedom to explore the data and analyze the results independent from any sponsor, and that they had sole authority to make the final decision to submit the material for publication.

Received for publication Aug 4, 2015; revisions received Feb 10, 2016; accepted for publication Feb 14, 2016; available ahead of print April 1, 2016.

Address for reprints: Bo Yang, MD, PhD, 5155 Frankel Cardiovascular Center, 1500 East Medical Center Dr, Ann Arbor, MI 48109 (E-mail: boya@med.umich.edu). 0022-5223/\$36.00

Copyright $(2) 2016$ by The American Association for Thoracic Surgery

http://dx.doi.org/10.1016/j.jtcvs.2016.02.038
Pulmonary hypertension $(\mathrm{PH})$ is a common complication of mitral stenosis. ${ }^{1}$ The risk of morbidity and mortality may be appreciably elevated in patients presenting with severe $\mathrm{PH}$ in conjunction with mitral stenosis. Indeed, the reported operative mortality of mitral valve surgery for mitral

Scanning this QR code will take you to supplemental figures for this article. 


$$
\begin{aligned}
& \text { Abbreviations and Acronyms } \\
& \begin{aligned}
\text { CAB } & =\text { coronary artery bypass } \\
\mathrm{CAD} & =\text { coronary artery disease } \\
\mathrm{CI} & =\text { confidence interval } \\
\mathrm{COPD} & =\text { chronic obstructive pulmonary disease } \\
\mathrm{CPB} & =\text { cardiopulmonary bypass } \\
\mathrm{MI} & =\text { myocardial infarction } \\
\mathrm{NYHA} & =\text { New York Heart Association } \\
\mathrm{OR} & =\text { odds ratio } \\
\mathrm{PAP} & =\text { pulmonary artery pressure } \\
\mathrm{PH} & =\text { pulmonary hypertension }
\end{aligned}
\end{aligned}
$$

stenosis with severe $\mathrm{PH}$ was as high as $30 \%$ in 1970 s. $^{2,3}$ Considering that mitral stenosis is not as common as mitral regurgitation in Western countries, limited data have been reported to date. Recent studies have indicated that mitral valve surgery can be performed in patients with mitral stenosis and severe $\mathrm{PH}$, with acceptable perioperative mortality rates ranging from $6 \%$ to $12 \%$. $^{4-7}$

Despite this evidence, however, severe $\mathrm{PH}$ remains a concern for cardiac surgeons when considering mitral valve surgery for patients with mitral stenosis. The consideration of mitral valve surgery for mitral stenosis should be guided by an assessment of the short-term as well as long-term risks of morbidity and mortality. Unfortunately, few studies to date have examined the long-term risks and benefits associated with mitral valve surgery with concomitant $\mathrm{PH} .{ }^{7} \mathrm{Cur}-$ rent guidelines do not report $\mathrm{PH}$ as an indication for surgical intervention or percutaneous mitral balloon commissurotomy for mitral stenosis, owing to a lack of evidence. ${ }^{8}$ There remains no consensus on the management of patients with mitral stenosis and $\mathrm{PH}$.

To address this knowledge gap, we summarized a 2decade experience with patients undergoing mitral valve surgery for mitral stenosis, and examined differences in short-term and long-term outcomes by increasing degree of $\mathrm{PH}$ at the time of mitral valve surgery.

\section{METHODS}

This study was approved by the Institutional Review Board at the University of Michigan Health System in compliance with Health Insurance Portability and Accountability Act regulations and the Declaration of Helsinki. A request for waiver of documentation of informed consent was approved for this retrospective study.

\section{Patient Selection}

Patients were identified for inclusion into this study based on the primary indication for operation as documented mitral stenosis between 1992 and 2014. The surgeons operated based on the presence of mitral stenosis and presentation of symptoms. The appropriate American College of Cardiologists/American Heart Association guidelines recommendations in place at the time of surgery served to define severe mitral stenosis. Investigators leveraged data from the University of Michigan's Department of Cardiac Surgery Data Warehouse. Subsequently, surgical reports were reviewed by a cardiac surgeon (B.Y.) to confirm mitral stenosis as the primary indication for surgery, as well as operative findings consistent with mitral stenosis. Finally, patient outcomes were verified and supplemented with a manual medical records review.

Additional inclusion criteria included documentation of pulmonary artery pressure (PAP) within 6 months before surgery. The PAP measurements were obtained before surgery from direct measurement during right heart catheterization, followed by estimation of right ventricle systolic pressure from echocardiography, and finally from Swan-Ganz right heart catheterization in the operating room before the start of the surgical procedure. Patients with concomitant aortic valve surgery were excluded.

\section{Assessments}

$\mathrm{PH}$ was defined as a mean PAP of $>25 \mathrm{~mm} \mathrm{Hg} .{ }^{9} \mathrm{PH}$ severity was based on systolic PAP and was categorized as follows: mild, 35 to $44 \mathrm{~mm} \mathrm{Hg}$; moderate, 45 to $59 \mathrm{~mm} \mathrm{Hg}$; and severe, $>60 \mathrm{~mm} \mathrm{Hg} .{ }^{10}$ Based on the mean and systolic PAP within 6 months before surgery, patients were divided into 4 groups: normal PAP, mild $\mathrm{PH}$, moderate $\mathrm{PH}$, and severe $\mathrm{PH}$.

\section{Demographic and Preoperative Data}

Demographic and preoperative data included age, sex, and preexisting comorbidities, including coronary artery disease (CAD), previous myocardial infarction (MI), right heart failure (defined as jugular vein distention $>10 \mathrm{~cm}$, ascites, or edema extending above knee level), New York Heart Association (NYHA) function classification, atrial fibrillation, chronic obstructive pulmonary disease (COPD), diabetes mellitus, renal disease (abnormal creatinine level), and previous cardiac surgery.

\section{Operative Data}

Operative data included type of mitral valve surgery (mitral valve replacement vs repair), other concomitant cardiac surgical procedures, cardiopulmonary bypass (CPB) duration, aortic cross-clamping duration, and blood transfusion. All operations were performed using cold crystalloid or blood cardioplegia and standard CPB.

\section{Short-Term and Long-Term Outcomes}

Short-term outcomes included a return to the operating room because of bleeding, postoperative stroke, new-onset renal failure requiring dialysis conditional on the absence of preoperative creatinine $>1.2,30$-day mortality, and duration of postsurgical hospitalization. Long-term survival data were obtained through the National Death Index database and were verified and supplemented by medical records review through December 2014 . $^{11}$

\section{Statistical Analysis}

Data are presented as mean \pm standard deviation for continuous data and as number and percentage for categorical data. Univariate comparisons across different PH groups were performed using the $\chi^{2}$ test for categorical data and Kruskal-Wallis one-way analysis of variance for continuous data. Multivariable logistic regression was used to report adjusted odds ratios (ORs), with $95 \%$ confidence intervals (CIs) of 30-day mortality among the groups adjusted for severe mitral regurgitation, age, severe tricuspid regurgitation, and right heart failure. Crude survival curves were estimated using the nonparametric Kaplan-Meier method. The log-rank test was used to compare survival among groups. Cox proportional hazard regression was used to calculate the adjusted hazard ratios (HRs), with $95 \%$ CIs adjusted for other risk factors, including severe mitral regurgitation, age, severe tricuspid regurgitation, and right heart failure. Proportional hazards assumption and the functional form of continuous variables were validated using supremum tests. A $P$ value $<.05$ (2-tailed) was considered statistically significant.

Because long-term survival was very similar in patients with normal PAP and those with mild $\mathrm{PH}$, as well as in those with moderate $\mathrm{PH}$ and severe $\mathrm{PH}$, we combined normal PAP and mild PH into one group and moderate and severe $\mathrm{PH}$ into another group for the analysis of long-term survival. All statistical calculations were performed using SAS 9.4 (SAS Institute, Cary, NC). 


\section{RESULTS}

A total of 317 patients were included in the analysis, including 31 with normal PAP $(10 \%), 64$ with mild PH $(20 \%), 94$ with moderate $\mathrm{PH}(30 \%)$, and 128 with severe $\mathrm{PH}(40 \%)$.

\section{Demographic Data and Preoperative Outcomes}

For the entire cohort $(\mathrm{n}=317)$, mean age was 61 years and $77 \%(\mathrm{n}=245)$ were female. Preoperative comorbidities included CAD $(29 \%)$, previous MI (12\%), renal failure $(10 \%)$, dialysis $(7 \%)$, atrial fibrillation $(45 \%)$, diabetes $(26 \%)$, COPD $(22 \%)$, severe mitral regurgitation $(19 \%)$, and emergent operation $(2 \%)$. There were no significant across-group differences by age, sex, preoperative comorbidities, severity of illness (as characterized by NYHA class), cardiac function (characterized by left ventricular ejection fraction) except severe tricuspid regurgitation $(P=.02)$ and right heart failure $(P=.03)$ (Table 1$)$.

\section{Intraoperative Outcomes}

In the entire cohort $(\mathrm{n}=317)$, there were more mitral valve replacements $(\mathrm{n}=248 ; 78 \%)$ than mitral valve repairs $(\mathrm{n}=69 ; 22 \%)$ (Table 2$)$. Concomitant surgical procedures included coronary artery bypass $(\mathrm{CAB} ; 12 \%)$, tricuspid valve repair or replacement $(33 \%)$, maze procedure $(26 \%)$, and other procedures $(12 \%)$. In the entire cohort, the mean cross-clamping time was $79 \pm 42$ minutes, and the mean $\mathrm{CPB}$ time was $113 \pm 51$ minutes. The rate of mitral valve replacement was higher in the moderate and severe $\mathrm{PH}$ groups compared with the normal PAP and mild PH groups, although the difference was not statistically significant. The severe PH group had significantly more patients with severe tricuspid regurgitation $(P=.02)$ (Table 1$)$, which was associated with more frequent tricuspid valve repair $(P=.0003)$ (Table 2). The $\mathrm{CPB}$ and cross-clamping times were significantly longer in the moderate-severe $\mathrm{PH}$ group compared with the normal PAP-mild PH group. Even though the overall blood transfusion was not significantly different between the 2 groups, the moderate-severe $\mathrm{PH}$ group received $>5$ units and more packed red blood cells $(P<.001)$ (Table 2$)$. There were no significant between-group differences in terms of other concomitant procedures, including $\mathrm{CAB}$, the maze procedure, and others (Table 2).

\section{Short-Term Outcomes}

Overall 30-day mortality, including intraoperative death and any death occurring within 30 days postsurgery, was $10 \%(\mathrm{n}=31)$. The overall postoperative cerebrovascular accident rate was $5 \%(\mathrm{n}=16)$, and the rate of new-onset renal failure on hemodialysis was $7 \%(\mathrm{n}=23)$. There were no significant differences in 30-day mortality among the normal PAP and PH groups (Table 3); however, because normal PAP and mild PH groups as well as moderate and severe PH groups behaved similarly, groups were combined. On logistic regression, 30-day mortality was significantly higher in the moderate-severe $\mathrm{PH}$ group compared with the normal PAP-mild PH group (12\% vs

TABLE 1. Demographic data and preoperative comorbidities $(n=317)$

\begin{tabular}{|c|c|c|c|c|c|}
\hline Group & $\begin{array}{l}\text { Normal PAP } \\
\quad(\mathbf{n}=\mathbf{3 1})\end{array}$ & $\begin{array}{l}\text { Mild PH } \\
(n=64)\end{array}$ & $\begin{array}{c}\text { Moderate PH } \\
\quad(n=94)\end{array}$ & $\begin{array}{c}\text { Severe PH } \\
(n=128)\end{array}$ & $P$ value \\
\hline $\mathrm{PAP}, \mathrm{mm} \mathrm{Hg}$, mean $\pm \mathrm{SD}$ & $20 \pm 4$ & $31 \pm 10$ & $35 \pm 95$ & $48 \pm 11$ & $<.0001$ \\
\hline Systolic PAP, mm Hg, mean \pm SD & $31 \pm 4$ & $39 \pm 4$ & $52 \pm 4$ & $76 \pm 13$ & $<.0001$ \\
\hline Age, $y r$, mean \pm SD & $62 \pm 13$ & $57 \pm 15$ & $61 \pm 14$ & $62 \pm 12$ & .26 \\
\hline Female sex, n $(\%)$ & $26(84)$ & $46(72)$ & $71(76)$ & $102(80)$ & .49 \\
\hline $\mathrm{CAD}, \mathrm{n}(\%)$ & $8(26)$ & $14(22)$ & $27(29)$ & $43(34)$ & .38 \\
\hline Previous MI, n (\%) & $3(10)$ & $5(8)$ & $14(15)$ & $16(13)$ & .59 \\
\hline Right heart failure, n (\%) & $1(3)$ & $4(7)$ & $6(7)$ & $20(17)$ & .03 \\
\hline Atrial fibrillation, n (\%) & $14(47)$ & $28(47)$ & $42(46)$ & $59(48)$ & .99 \\
\hline Previous cardiac surgery, n (\%) & $4(13)$ & $11(17)$ & $24(26)$ & $37(29)$ & .14 \\
\hline COPD, n $(\%)$ & $5(17)$ & $10(17)$ & $19(21)$ & $35(28)$ & .25 \\
\hline Diabetes, $\mathrm{n}(\%)$ & $5(16)$ & $13(20)$ & $23(25)$ & $42(33)$ & .12 \\
\hline Renal disease, $\mathrm{n}(\%)$ & $2(7)$ & $1(2)$ & $9(10)$ & $12(10)$ & .21 \\
\hline Emergent operation, $\mathrm{n}(\%)$ & $0(0)$ & $1(2)$ & $1(1)$ & $4(3)$ & .70 \\
\hline Severe TR, n $(\%)$ & $3(12)$ & $6(11)$ & $14(19)$ & $31(31)$ & .02 \\
\hline Severe MR, n (\%) & $8(33)$ & $12(24)$ & $14(19)$ & $26(27)$ & .49 \\
\hline NYHA function class III/IV, $\mathrm{n}(\%)$ & $19(68)$ & $42(71)$ & $69(84)$ & $91(79)$ & .16 \\
\hline $\mathrm{EF}, \mathrm{n}(\%)$ & & & & & .62 \\
\hline$<40$ & $3(21)$ & $1(7)$ & $3(21)$ & $5(36)$ & - \\
\hline $40-55$ & $3(12)$ & $6(23)$ & $7(27)$ & $8(31)$ & - \\
\hline$>55$ & $9(8)$ & $19(17)$ & $34(31)$ & $42(39)$ & - \\
\hline
\end{tabular}

Mild PH, 35-44 mm Hg; moderate PH, $45-59 \mathrm{~mm} \mathrm{Hg}$; severe $\mathrm{PH} \geq 60 \mathrm{~mm} \mathrm{Hg}$. Applies to all outcomes without units [yes, (\%)]. PAP, Pulmonary artery pressure; $P H$, pulmonary hypertension; $S D$, standard deviation; $C A D$, coronary artery disease; $M I$, myocardial infarction; $C O P D$, chronic obstructive pulmonary disease; $T R$, tricuspid regurgitation; $M R$, mitral regurgitation; NYHA, New York Heart Association; $E F$, ejection fraction. 
TABLE 2. Intraoperative outcomes of patients with mitral stenosis and PH $(n=317)$

\begin{tabular}{|c|c|c|c|c|c|}
\hline Group & $\begin{array}{l}\text { Normal PAP } \\
\quad(\mathbf{n}=\mathbf{3 1})\end{array}$ & $\begin{array}{l}\text { Mild PH } \\
(n=64)\end{array}$ & $\begin{array}{c}\text { Moderate PH } \\
\quad(n=94)\end{array}$ & $\begin{array}{c}\text { Severe PH } \\
(n=128)\end{array}$ & $P$ value \\
\hline Mitral replacement, n (\%) & $20(65)$ & $45(69)$ & $79(84)$ & $104(81)$ & .04 \\
\hline Mitral repair, n (\%) & $11(36)$ & $20(31)$ & $18(19)$ & $26(20)$ & .09 \\
\hline CAB concomitant, n (\%) & $5(16)$ & $5(8)$ & $8(8)$ & $20(16)$ & .23 \\
\hline TV concomitant, $\mathrm{n}(\%)$ & $7(23)$ & $12(19)$ & $26(28)$ & $59(46)$ & .0003 \\
\hline Maze concomitant, $\mathrm{n}(\%)$ & $8(26)$ & $16(25)$ & $23(25)$ & $34(27)$ & .98 \\
\hline Other concomitant, $\mathrm{n}(\%)$ & $3(10)$ & $6(10)$ & $11(12)$ & $18(14)$ & .77 \\
\hline $\mathrm{CPB}$ time, min, mean $\pm \mathrm{SD}$ & $99 \pm 27$ & $99 \pm 39$ & $116 \pm 46$ & $122 \pm 60$ & .001 \\
\hline Cross-clamp time, min, mean $\pm \mathrm{SD}$ & $74 \pm 25$ & $68 \pm 38$ & $82 \pm 43$ & $84 \pm 43$ & .025 \\
\hline RBC transfusions, $\mathrm{n}(\%)$ & $20(71)$ & $36(61)$ & $61(74)$ & $95(75)$ & .23 \\
\hline RBC transfusions, units, $\mathrm{n}(\%)$ & & & & & $<.0001$ \\
\hline 0 & $8(29)$ & $23(39)$ & $22(27)$ & $31(25)$ & \\
\hline $1-2$ & $6(21)$ & $24(41)$ & $33(40)$ & $46(37)$ & \\
\hline $3-4$ & $12(43)$ & $10(17)$ & $14(17)$ & $29(23)$ & \\
\hline $5+$ & $2(7)$ & $2(3)$ & $14(17)$ & $20(16)$ & \\
\hline
\end{tabular}

Mild PH, 35-44 mm Hg; moderate PH, 45-59 mm Hg; severe PH, $\geq 60 \mathrm{~mm} \mathrm{Hg}$; applies to all outcomes without units [yes, (\%)]. PAP, Pulmonary artery pressure; PH, pulmonary hypertension; $C A B$, coronary artery bypass; $T V$, tricuspid valve; $C P B$, cardiopulmonary bypass; $S D$, standard deviation; $R B C$, red blood cell.

$5 \%$ ). The OR of 30-day mortality for the moderate-severe PH group versus the normal PAP-mild PH group was 5.04 $(95 \%$ CI, 1.13-22.5; $P=.03)$. Patients with severe PH had a significantly higher incidence of new-onset renal failure requiring dialysis $(P=.01)$ and longer duration of postsurgical hospitalization $(P=.003)$ compared with those with normal PAP, mild PH, or moderate PH (Table 3). There were no significant between-group differences in 30-day mortality in patients undergoing mitral valve replacement and those undergoing mitral valve repair $(6.5 \%$ vs $4.3 \%)$. In the mitral valve replacement subgroup, 99 patients $(40 \%)$ received a mechanical valve and $149(60 \%)$ received a bioprosthesis. The 30-day mortality was higher in the mechanical valve recipients than in the bioprosthesis recipients, but not significantly so $(7 \%$ vs $1.4 \% ; P=.09$ ).

\section{Long-Term Survival}

The total patient-years of follow-up for each group were 286 in the normal PAP group, 550 in the mild PH group, 650 in the moderate $\mathrm{PH}$ group, and 863 in the severe $\mathrm{PH}$ group. The overall mortality of the entire cohort over the 22-year study period was $31 \%(\mathrm{n}=97)$, and the mortality rate did not change appreciably over time during the study period. By group, the mortality rate per 100 patient-years was 1.4 in the normal PAP group, 2.7 in the mild PH group, 5.1 in the moderate $\mathrm{PH}$ group, and 5.2 in the severe $\mathrm{PH}$ group. There was no significant difference in long-term survival between moderate $\mathrm{PH}$ and severe $\mathrm{PH}$ groups or between the normal PAP and mild PH groups. Long-term survival was significantly lower in the moderate $\mathrm{PH}$ and severe $\mathrm{PH}$ groups compared with the normal PAP and mild $\mathrm{PH}$ groups using Kaplan-Meier curve analysis $(P=.020, \log$ rank test) (Figure 1, $A$ ). The difference in long-term survival became apparent when the groups were combined (moderate-severe PH group [n $=222]$ vs normal PAP-mild PH group $[\mathrm{n}=95] ; P=.003, \log$-rank test) (Figure $1, B)$. After controlling for age, right heart failure, severe tricuspid regurgitation, and severe mitral regurgitation, 10-year survival was $58 \%$ in the moderate-severe $\mathrm{PA}$ group and $83 \%$ in the normal PAP-mild PH group, and 12-year survival was $51 \%$ in the moderate-severe $\mathrm{PA}$ group and $79 \%$ in the normal PAP-mild PH group $(P<.05$ for both 10-year and 12-year mortality). The risk-adjusted HR in moderate-severe $\mathrm{PH}$ group versus the normal PAP-mild $\mathrm{PH}$ group was $2.98(95 \% \mathrm{CI}, 1.55-5.75 ; P=.001)$ when controlling for age, right heart failure, severe tricuspid regurgitation, and severe mitral regurgitation (Figure 2). When the PAP was used as a continuous variable, the 10year survival of patients after mitral valve surgery for mitral

TABLE 3. Short-term outcomes of patients with mitral stenosis and $\mathrm{PH}(\mathrm{n}=317)$

\begin{tabular}{|c|c|c|c|c|c|}
\hline Group & $\begin{array}{l}\text { Normal PAP } \\
\quad(\mathbf{n}=\mathbf{3 1})\end{array}$ & $\begin{array}{c}\text { Mild PH } \\
(n=64)\end{array}$ & $\begin{array}{c}\text { Moderate PH } \\
(n=94)\end{array}$ & $\begin{array}{c}\text { Severe PH } \\
(n=128)\end{array}$ & $P$ value \\
\hline Reoperation for bleeding, $\mathrm{n}(\%)$ & 0 & 0 & 0 & $1(1)$ & - \\
\hline CVA, n $(\%)$ & 0 & $5(8)$ & $7(8)$ & $4(3)$ & .20 \\
\hline New-onset renal failure on dialysis, $\mathrm{n}(\%)$ & $4(13)$ & $0(0)$ & $5(6)$ & $14(11)$ & .010 \\
\hline 30-d mortality, $\mathrm{n}(\%)$ & $1(3)$ & $4(6)$ & $14(15)$ & $12(9)$ & .15 \\
\hline $\mathrm{LOS}, \mathrm{d}$, mean $\pm \mathrm{SD}$ & $11 \pm 9$ & $9 \pm 6$ & $12 \pm 9$ & $18 \pm 26$ & .003 \\
\hline
\end{tabular}

Mild PH, 35-44 mm Hg; moderate PH, 45-59 mm Hg; severe PH, $\geq 60 \mathrm{~mm} \mathrm{Hg}$; applies to all outcomes without units [yes, (\%)]. PAP, Pulmonary artery pressure; $P H$, pulmonary hypertension; $C V A$, cerebrovascular accident; $L O S$, length of stay; $S D$, standard deviation. 

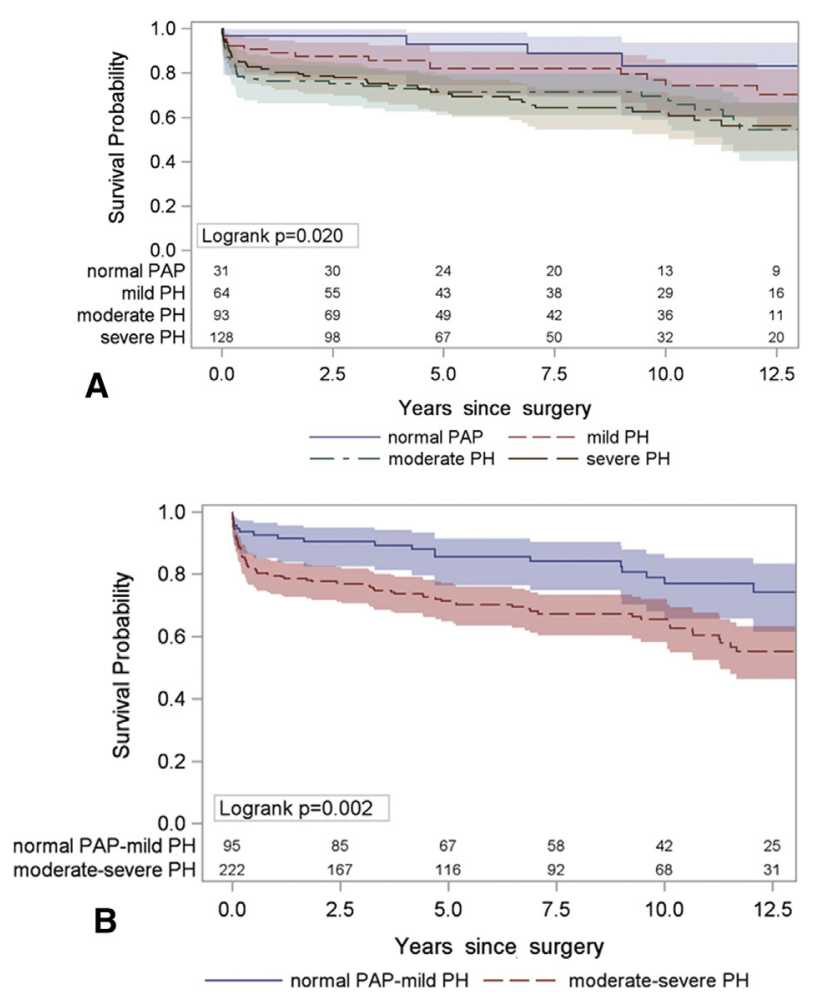

FIGURE 1. A, Kaplan-Meier survival stratified by systolic PAP. PH was categorized as mild (35-44 mm Hg), moderate (45-59 mm Hg), or severe ( $>60 \mathrm{~mm} \mathrm{Hg}$ ). The curves were truncated at 12.5 years because no events were observed thereafter. B, Kaplan-Meier survival stratified by systolic PAP in the normal PAP-mild PH group and the moderate-severe PH group. The curves were truncated at 12.5 years because no events were observed thereafter. $P A P$, Pulmonary artery pressure; $P H$, pulmonary hypertension.

stenosis was inversely associated with the PAP before surgery (Figure 3).

Long-term (ie, 12-year) survival did not differ significantly between patients undergoing mitral valve replacement and those undergoing mitral valve repair using Kaplan-Meier survival analysis and a Cox regression model. With controlling for PAP, age, right heart failure, severe tricuspid regurgitation, and severe mitral regurgitation, the risk-adjusted $\mathrm{HR}$ for mitral valve replacement versus mitral valve repair was 0.97 (95\% CI, 0.49-1.92; $P=.93)$. In addition, long-term survival was not affected by the type of valve used for replacement, a mechanical valve or a bioprosthesis, with an HR of 0.91 (95\% CI, $0.49-1.69 ; P=.76)$ when controlling for PAP, age, right heart failure, severe tricuspid regurgitation, and severe mitral regurgitation.

\section{DISCUSSION}

Here we report the short-term and long-term survival of patients undergoing mitral valve surgery for mitral stenosis and $\mathrm{PH}$. The 30-day mortality in the severe $\mathrm{PH}$ group was $9 \%$, and no significant between-group differences were noted; however, 30-day mortality was more than doubled in

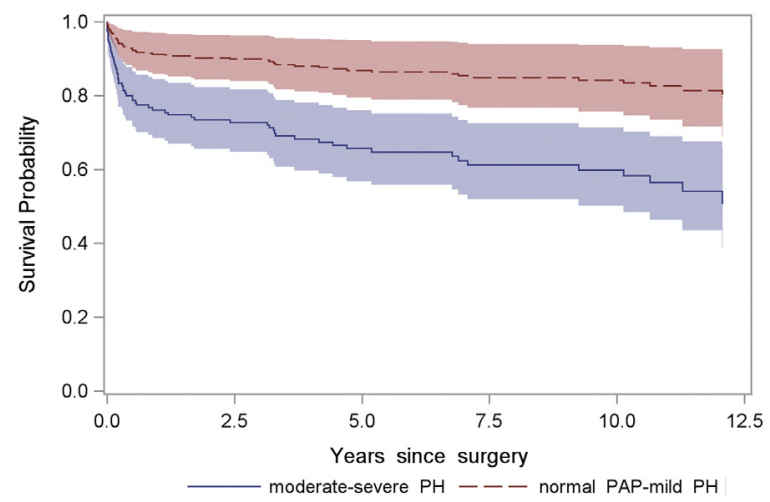

FIGURE 2. Survival probability of patients based on degree of PH. A Cox proportional hazard model was developed to assess the effect of $\mathrm{PH}$ on time to death, adjusting for covariates including age, severe mitral valve regurgitation, status of severe tricuspid valve regurgitation, and history of right heart failure. The survival probability shown here is calculated given patient characteristics of age 61 years with no severe tricuspid valve regurgitation, no right heart failure, and no severe mitral valve regurgitation. The HR of death in patients with moderate or severe $\mathrm{PH}$ was $2.98(95 \% \mathrm{CI}$, 1.54-5.75), exceeding that in the patients with normal PAP or mild $\mathrm{PH}$. $P H$, Pulmonary hypertension; $P A P$, pulmonary artery pressure.

the combined moderate-severe $\mathrm{PH}$ group compared with the combined normal PAP-mild PH group. Long-term survival (ie, 12 years) was also worse in the moderate-severe $\mathrm{PH}$ group compared with the normal PAP-mild $\mathrm{PH}$ group (51\% vs $79 \%)$.

A common complication of mitral stenosis is $\mathrm{PH}$, which has been considered a high-risk factor for patients with mitral stenosis undergoing mitral valve surgery. Historical studies from the 1970s and 1980s report operative mortality ranging from $15 \%$ to $31 \%$ in this patient population. ${ }^{2,12,13}$ In general, cardiac surgeons are hesitant to operate on patients with mitral stenosis and severe $\mathrm{PH}$,

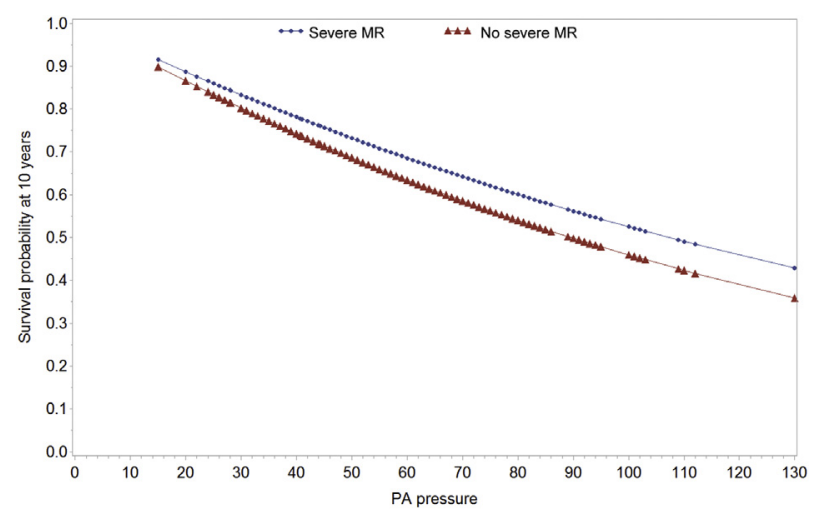

FIGURE 3. Survival probability at 10 years for patients against PAP as a continuous variable. A Cox proportional hazard model was developed with $\log$-transformed PAP as the exposure of interest. The survival probability shown here was calculated given patient characteristics of age 61 years with no severe tricuspid valve regurgitation and no right heart failure, with or without severe mitral valve regurgitation. $M R$, Mitral regurgitation; $P A$, pulmonary artery. 
because severe $\mathrm{PH}$ has been associated with right heart failure and operative mortality ${ }^{3}$; however, most cardiac surgeons would agree that a patient might be a surgical candidate if $\mathrm{PH}$ decreases significantly on inhalation of nitric oxide during right heart catheterization. More recent studies have shown improved operative mortality ranging from $5.6 \%$ to $11.6 \%$, with neither pulmonary vascular resistance nor severe $\mathrm{PH}$ predictive of perioperative mortality or major complications..$^{4-7}$ It has been concluded that mitral valve surgery can be performed with acceptable perioperative mortality in patients with mitral stenosis and severe $\mathrm{PH}$. Our intraoperative and 30-day mortality rates of $1 \%$ and $9 \%$, respectively, further support the view that severe $\mathrm{PH}$ is not a contraindication for mitral valve surgery. At our institution, the reported mortality is higher for this population compared with that for patients undergoing mitral valve surgery for degenerative mitral valve disease, because those patients were much sicker than those who may have presented to our institution with mitral regurgitation from degenerative mitral valves. Based on our experience, we operate on patients with PAP above systemic blood pressure; however, it is not routine to perform right heart catheterization with inhaled nitric oxide to study the response of pulmonary vasculature to nitric oxide. We have found that inhaled nitric oxide as needed is helpful in managing $\mathrm{PH}$ after mitral valve surgery.

Although our patients with mitral stenosis and $\mathrm{PH}$ survived mitral valve surgery with acceptable 30-day mortality, long-term survival was decreased, as evidenced by the 12-year survival rate of $51 \%$ identified in the combined moderate-severe $\mathrm{PH}$ group, which was significantly worse than the rate of $79 \%$ in the normal PAP-mild $\mathrm{PH}$ group (Figure $1, B$ ). The HR was $\sim 3$, indicating that at any time point after mitral valve surgery, the risk of death was nearly threefold greater in the patients with mitral stenosis and moderate to severe PH compared with those with mitral stenosis and normal PAP or mild PH (Figure 2). If we use PAP as a continuous variable instead of artificially dividing it into 2 categories of normal PAP and mild, moderate and severe $\mathrm{PH}$, then the 10-year survival is inversely associated with preoperative PAP (Figure 3). The 10-year survival seemed worse in patients with $\mathrm{PH}$ resulting from mitral stenosis compared with those with $\mathrm{PH}$ resulting from the combination of mitral stenosis and severe mitral regurgitation (Figure 3), although this study was not designed to investigate this question. This finding is consistent with the observation that $\mathrm{PH}$ seemed to have less impact on long-term survival in patients with mitral regurgitation. ${ }^{14}$ Given our lack of follow-up PAP data to understand how PH evolves after mitral valve surgery in patients with mitral stenosis, we can only speculate that the higher mortality in the moderate-severe $\mathrm{PH}$ group may be due to persistent $\mathrm{PH}$ even after mitral valve surgery in these patients. Thus, treating
PH in patients with mitral stenosis after mitral valve surgery may be beneficial.

Although the mechanism is unclear, the data support our hypothesis that performing mitral valve surgery in patients with mitral stenosis before the development of moderate $\mathrm{PH}$ can improve long-term survival. Vincens and colleagues ${ }^{7}$ reported a 10-year survival of $64 \%$ for patients with mitral stenosis and severe $\mathrm{PH}$ after mitral valve surgery, which is close to the 10 -year survival rate $(58 \%)$ reported here in our combined moderate-severe $\mathrm{PH}$ group. The difference may be explained by our higher proportions of patients with severe $\mathrm{PH}$ and with comorbidities (ie, diabetes, renal failure, and tricuspid procedures). Furthermore, we excluded patients who underwent aortic valve replacement, but included patients who underwent the maze procedure and ascending aorta or aortic arch replacement, whereas Vincen and colleagues included patients with aortic valve replacement.

For patients with mitral regurgitation, the current guidelines clearly state that surgery should be considered when PAP is $>50 \mathrm{~mm} \mathrm{Hg}$, but do not contain a clear recommendation regarding $\mathrm{PH}$ for patients with mitral stenosis and $\mathrm{PH}^{8}{ }^{8}$ Based on our findings, we recommend considering surgical intervention for patients with mitral stenosis before the development of moderate to severe PH (PAP $>45 \mathrm{~mm}$ $\mathrm{Hg}$ ) to improve long-term survival. Percutaneous balloon valvuloplasty could be a valid option to relieve mitral stenosis if the valvuloplasty score is low and the patient is a candidate for the procedure based on current guidelines. ${ }^{8}$ However, surgical intervention should be considered for patients who have calcified mitral valves and are not candidates for percutaneous balloon valvuloplasty, such as the patients in our study.

In patients with mitral regurgitation, mitral valve repair improves long-term survival compared with mitral valve replacement. ${ }^{15-17}$ Whether patients with mitral stenosis benefit from mitral valve repair remains unknown. In our study, unsurprisingly, $78 \%$ of the patients with mitral stenosis underwent mitral valve replacement $(40 \%$ with a mechanical valve and $60 \%$ with a bioprosthesis) because of a destroyed mitral valve and subvalvular apparatus, and $22 \%$ of the patients underwent mitral repair, mainly commisurotomy. The 30-day mortality and 12-year mortality were not significantly different between mitral valve repair and mitral valve replacement for the patients with mitral stenosis, or in the subgroups of patients undergoing mitral valve replacement with a mechanical valve or a bioprosthesis. This finding suggests that both mitral valve replacement with a mechanical valve or bioprosthesis and mitral valve repair are appropriate operations for mitral stenosis.

This study has some limitations. Our cohort includes some patients $(\mathrm{n}=101)$ who underwent mitral valve surgery for mitral stenosis but with unknown PAP data because 
of missing records or PAP measurements performed beyond 6 months prior to surgery between 1992 and 2014. Those patients were not included in our analysis. The long-term survival of this group was similar to that of the normal PAP group (Figure E1), suggesting that patients with unknown PAP most likely were patients who did not have $\mathrm{PH}$ and thus did not have PAP measured. Almost all $(95 \%)$ of the patients with unknown PAP underwent surgery between 1992 and 2002. Considering only the patients from 2003 to 2014 , a total of 218 patients including $6(2.8 \%)$ with unknown PAP, the differences in long-term survival (Figure E2) and HR (3.3; 95\% CI, 1.3-8.6) in the moderate-severe $\mathrm{PH}$ group compared with the normal PAP-mild $\mathrm{PH}$ group were very similar to those calculated with all 317 cases occurring between 1992 to 2014 (Figures 1, B and 2). The 30-day mortality did not change over time.

We believe that excluding the patients with unknown PAP data from our analysis does not change our overall conclusions. The medical records in the early stage (1992-2002) were less complete than those from 2003 to 2014. We did not have complete records of the severity of mitral stenosis, especially in the early stage; however, the surgeons at our institution followed current surgical guidelines for patients with mitral stenosis. We reviewed all operative reports to confirm that mitral stenosis was the primary indication for mitral valve surgery, the operative finding consistent with mitral stenosis, and that the operative procedures were for mitral stenosis (commisurotomy or replacement). We are confident that all of the patients in our study most likely had severe mitral stenosis. We have very limited data on postoperative PAP and other information, such as causes of death, cardiac events, and quality of life. This study was not designed to test the short-term and long-term outcomes of mitral valve repair and replacement and was not powered for that purpose. This limitation weakens our conclusion regarding mitral valve repair and replacement in patients with mitral stenosis.

In conclusion, mitral valve surgery can be performed with acceptable 30-day mortality in patients with mitral stenosis and moderate to severe $\mathrm{PH}$; however, long-term survival is impaired by the development of moderate to severe $\mathrm{PH}$. Patients with mitral stenosis and mild PH (systolic PAP, 35$44 \mathrm{~mm} \mathrm{Hg}$ ) but minimal symptoms should undergo mitral valve surgery merely to potentially forestall further worsening PH and improve long-term survival.

\section{Conflict of Interest Statement}

Authors have nothing to disclose with regard to commercial support.
We thank Frank Pagani, MD, Himanshu Patel, MD, Jonathon Haft, MD, Matthew Romano, MD, Richard Prager, MD, and G. Michael Deeb, MD, for contributing cases from the University of Michigan Health System, Frankel Cardiovascular Center.

\section{References}

1. Chandrashekhar Y, Westaby S, Narula J. Mitral stenosis. Lancet. 2009;374: 1271-83.

2. Ward C, Hancock BW. Extreme pulmonary hypertension caused by mitral valve disease: natural history and results of surgery. Br Heart J. 1975;37:74-8.

3. Najafi H, Dye WS, Javid H, Hunter JA, Ostermiller WE Jr, Julian OC. Mitral valve replacement: review of seven years' experience. Am J Cardiol. 1969;24: 386-92.

4. Cámara ML, Aris A, Padró JM, Caralps JM. Long-term results of mitral valve surgery in patients with severe pulmonary hypertension. Ann Thorac Surg. 1988;45:133-6.

5. McIlduff JB, Daggett WM, Buckley MJ, Lappas DG. Systemic and pulmonary hemodynamic changes immediately following mitral valve replacement in man. J Cardiovasc Surg (Torino). 1980;21:261-6.

6. Mubeen M, Singh AK, Agarwal SK, Pillai J, Kapoor S, Srivastava AK. Mitral valve replacement in severe pulmonary arterial hypertension. Asian Cardiovasc Thorac Ann. 2008;16:37-42.

7. Vincens JJ, Temizer D, Post JR, Edmunds LH Jr, Herrmann HC. Long-term outcome of cardiac surgery in patients with mitral stenosis and severe pulmonary hypertension. Circulation. 1995;92(9 Suppl):II137-42.

8. Nishimura RA, Otto CM, Bonow RO, Carabello BA, Erwin JP III, Guyton RA, et al. 2014 AHA/ACC guideline for the management of patients with valvular heart disease: executive summary. A report of the American College of Cardiology/American Heart Association Task Force on Practice Guidelines. Circulation. 2014;129:2440-92.

9. Galiè N, Hoeper MM, Humbert M, Torbicki A, Vachiery JL, Barbera JA, et al. Guidelines for the diagnosis and treatment of pulmonary hypertension: the Task Force for the Diagnosis and Treatment of Pulmonary Hypertension of the European Society of Cardiology (ESC) and the European Respiratory Society (ERS), endorsed by the International Society of Heart and Lung Transplantation (ISHLT). Eur Heart J. 2009;30:2493-537.

10. Zlotnick DM, Ouellette ML, Malenka DJ, DeSimone JP, Leavitt BJ, Helm RE, et al. Effect of preoperative pulmonary hypertension on outcomes in patients with severe aortic stenosis following surgical aortic valve replacement. Am J Cardiol. 2013;112:1635-40.

11. Centers for Disease Control and Prevention. National Death Index. Available at: http://www.cdc.gov/nchs/ndi.htm. Accessed January 21, 2016.

12. Scott JA, Khaw BA, Locke E, Haber E, Homcy C. The role of free radical-mediated processes in oxygen-related damage in cultured murine myocardial cells Circ Res. 1985;56:72-7.

13. Zener JC, Hancock EW, Shumway NE, Harrison DC. Regression of extreme pul monary hypertension after mitral valve surgery. Am J Cardiol. 1972;30:820-6.

14. Enter DH, Zaki A, Duncan B, McCathy P. A contemporary analysis of pulmonary hypertension in patients undergoing mitral valve surgery: is this a risk factor? Available at: http://webcast.aats.org/2015/Presentations_2/4E/04272015/1400Adult $\% 20$ Cardiac $\% 20$ S3/1555_Enter_D/PHTN_AATS_DE.pdf. Accessed January 5, 2016.

15. Enriquez-Sarano M, Schaff HV, Orszulak TA, Tajik AJ, Bailey KR, Frye RL. Valve repair improves the outcome of surgery for mitral regurgitation: a multivariate analysis. Circulation. 1995;91:1022-8.

16. Goldman ME, Mora F, Guarino T, Fuster V, Mindich BP. Mitral valvuloplasty is superior to valve replacement for preservation of left ventricular function: an intraoperative two-dimensional echocardiographic study. J Am Coll Cardiol. 1987; 10:568-75.

17. Cosgrove DM, Stewart WJ. Mitral valvuloplasty. Curr Probl Cardiol. 1989;14: $359-415$.

Key Words: mitral stenosis, pulmonary hypertension, survival 


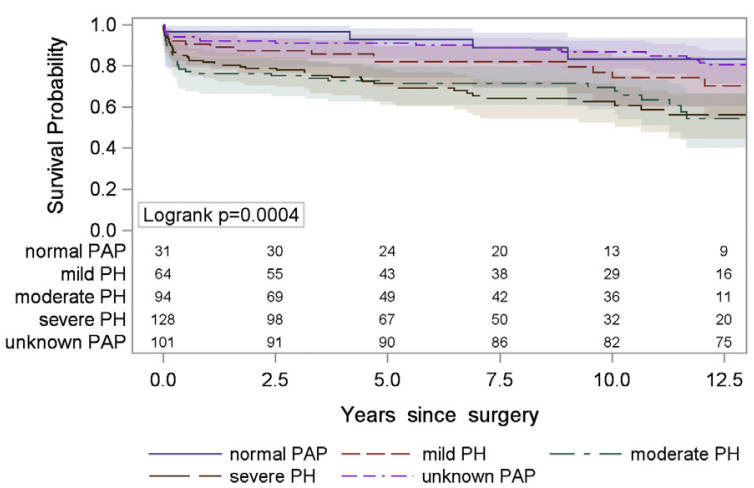

FIGURE E1. Kaplan-Meier survival stratified by systolic PAP. PH was categorized as follows: mild, 35 to $44 \mathrm{~mm} \mathrm{Hg}$; moderate, 45 to $59 \mathrm{~mm}$ $\mathrm{Hg}$; severe, $>60 \mathrm{~mm} \mathrm{Hg}$; and unknown PAP. The curve was truncated at 12.5 years because no major events were observed thereafter. $P A P$, Pulmonary artery pressure; $P H$, pulmonary hypertension.

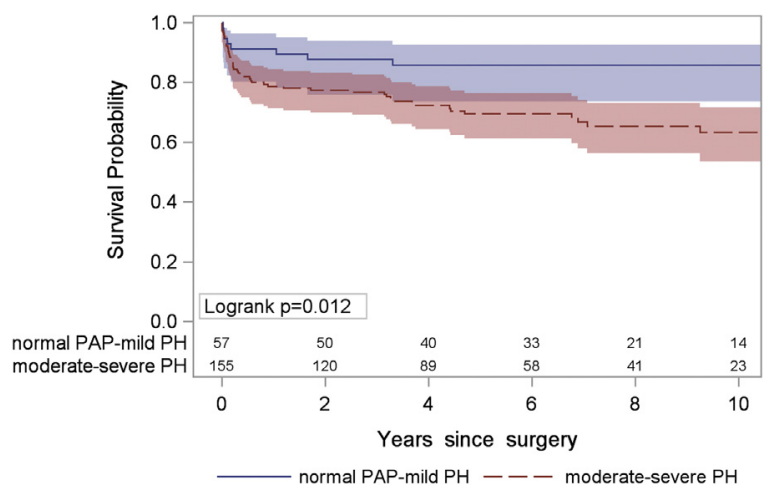

FIGURE E2. Kaplan-Meier survival stratified by systolic PAP using cases from 2003 to 2014 in the combined normal PAP-mild PH group versus the moderate-severe PH group. This cohort was from 2003 to 2014, which had a total of 218 patients, with 6 patients $(2.7 \%)$ with unknown PAP. PAP, Pulmonary artery pressure; $P H$, pulmonary hypertension. 